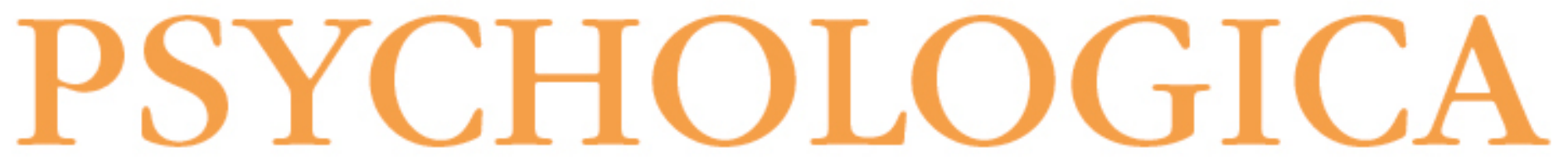

\title{
Preconceito e descontextualização normativa: considerações metodológicas ilustradas pelas representações sobre AIDS na Africa e Africano
}

\begin{tabular}{|c|c|}
\hline Autor(es): & $\begin{array}{l}\text { Danfá, Lassana; Aléssio, Renata Lira dos Santos; Santos, Maria de } \\
\text { Fátima de Souza; Morais, Edclécia Reino Carneiro de }\end{array}$ \\
\hline Publicado por: & Imprensa da Universidade de Coimbra \\
\hline $\begin{array}{l}\text { URL } \\
\text { persistente: }\end{array}$ & URI:http://hdl.handle.net/10316.2/43291 \\
\hline DOI: & DOI:https://doi.org/10.14195/1647-8606_60-2_5 \\
\hline Accessed: & 26-Apr-2023 14:04:52 \\
\hline
\end{tabular}

A navegação consulta e descarregamento dos títulos inseridos nas Bibliotecas Digitais UC Digitalis, UC Pombalina e UC Impactum, pressupõem a aceitação plena e sem reservas dos Termos e Condições de Uso destas Bibliotecas Digitais, disponíveis em https://digitalis.uc.pt/pt-pt/termos.

Conforme exposto nos referidos Termos e Condições de Uso, o descarregamento de títulos de acesso restrito requer uma licença válida de autorização devendo o utilizador aceder ao(s) documento(s) a partir de um endereço de IP da instituição detentora da supramencionada licença.

Ao utilizador é apenas permitido o descarregamento para uso pessoal, pelo que o emprego do(s) título(s) descarregado(s) para outro fim, designadamente comercial, carece de autorização do respetivo autor ou editor da obra.

Na medida em que todas as obras da UC Digitalis se encontram protegidas pelo Código do Direito de Autor e Direitos Conexos e demais legislação aplicável, toda a cópia, parcial ou total, deste documento, nos casos em que é legalmente admitida, deverá conter ou fazer-se acompanhar por este aviso.

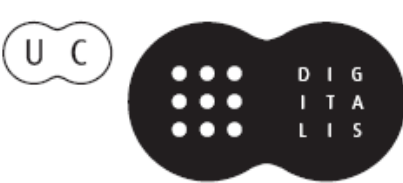




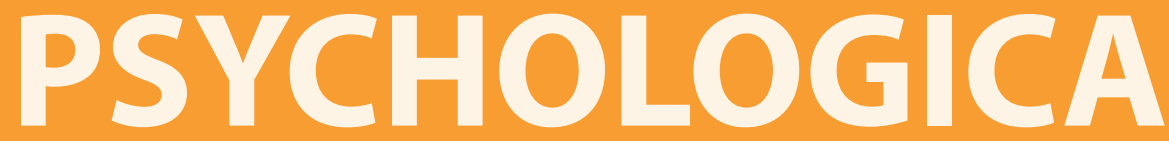




\title{
Preconceito e descontextualização normativa: considerações metodológicas ilustradas pelas representações sobre AIDS na África e Africano
}

\section{Lassana Danfá1, Renata Lira dos Santos Aléssio², Maria de Fátima de Souza Santos ${ }^{3}$ e Edclécia Reino Carneiro de Morais ${ }^{4}$}

Prejudice and Normative Decontextualization: methodological considerations illustrated by the representation of AIDS in Africa and African

\begin{abstract}
This article aims to discuss methodological implications of normative decontextualization technique and the control of the presentation order of inductive terms in a free association task, from the study of social representations of AIDS in Africa and the African with 60 Brazilian university students. Two researchers (one Brazilian and one African) applied a word evocation questionnaire with control of the presentation order of the inductors. The correspondence analysis of the lexical fields, by the software Tri-deux-mots, allowed to identify that the manipulated variables activated representational contents that were connected to distinct psychosocial processes: causal attribution and stereotypes production. The expression AIDS in Africa when presented in first order inducts the attribution of
\end{abstract}

1 Psicólogo, mestre e doutorando em Psicologia pela Universidade Federal de Pernambuco. Email: delassanadanfa@hotmail.com

2 Professora Adjunta do Departamento de Psicologia e do Programa de Pós-Graduação em Psicologia da Universidade Federal de Pernambuco. Email: renatalir@gmail.com

3 Professora Titular da Universidade Federal de Pernambuco, no Departamento de Psicologia e de Programa de Pós-graduação em Psicologia. Email: fatimasan@uol.com.br

4 Psicóloga, mestra e doutoranda em Psicologia pela Universidade Federal de Pernambuco. Email: edclecia@gmail.com 
the external cause. The expression African inducts the attribution of internal cause. In the presence of the African researcher more positive contents were evoked when compared with the presence of the Brazilian researcher. This stereotype game brings into focus a subtle manifestation of prejudice.

Keywords: normative decontextualization; prejudice; AIDS; social representations; Africa.

\section{Resumo}

Este artigo objetivou discutir implicações metodológicas da técnica de descontextualização normativa e do controle da ordem de apresentação de termos indutores em uma tarefa de associação livre, a partir do estudo das representações sociais sobre AIDS na África e sobre o Africano com 60 universitários brasileiros. Dois pesquisadores (brasileiro e africano) aplicaram um questionário de evocação de palavras com controle da ordem de apresentação dos indutores. A análise de correspondência dos campos lexicais, pelo software Tri-deux-mots, permitiu identificar que as variáveis manipuladas ativaram conteúdos representacionais ligados a processos psicossociais distintos: atribuição de causalidade e produção de estereótipos. A expressão AIDS na África quando apresentada em primeira ordem induz a atribuição de causalidade externa. Já a expressão Africano induz atribuição de causalidade interna. Na presença do pesquisador africano mais conteúdos positivos foram evocados, quando comparados com a presença do pesquisador brasileiro. Esse jogo de estereótipos traz à tona uma manifestação sutil do preconceito.

Palavras-chave: descontextualização normativa; preconceito; AIDS; representações sociais; África.

\section{INTRODUÇÃO}

O presente artigo tem como objetivo discutir as implicações metodológicas da técnica de descontextualização normativa e do controle da ordem de apresentação de termos indutores em uma tarefa de associação livre, para produção e análise de conteúdos representacionais, a partir do estudo das representações sociais de estudantes universitários brasileiros sobre a AIDS na África e sobre o Africano.

As representações sociais (RS) são conceituadas por Moscovici (2012) como um conjunto de crenças e saberes construídos e partilhados socialmente, através dos quais nós pensamos, falamos, decidimos o que fazer, dando sentido ao mundo. Trata-se de uma modalidade do conhecimento que tem como função dar sentido 
à realidade social, orientar comportamentos, organizar as comunicações entre os indivíduos e produzir identidades. Estas modalidades do pensamento estão fincadas na comunicação e nas práticas sociais, isto é, nos diálogos, nos eventos ritualísticos, nos padrões de trabalho e produção, na arte e na própria cultura. São estratégias que os atores sociais desenvolvem para lidar com a diversidade e mobilidade do mundo, que transcende individualmente cada sujeito. Assim, a representação social é um espaço potencial de construção coletiva, no qual os sujeitos vão além da própria individualidade, entrando no domínio do espaço público ou da vida comum (Jovchelovitch, 2012).

O campo de estudos sobre representações sociais possui algumas vertentes teórico-metodológicas que têm objetivos específicos na investigação do fenômeno. A abordagem culturalista desenvolvida por Denise Jodelet (1989) enfatiza o estudo de objetos culturalmente relevantes e sensíveis do ponto de vista sócio-histórico e político. Com ênfase em metodologias qualitativas, estes estudos se caracterizam por problematizar a influência da cultura na construção de fenômenos representacionais e sua implicação na dinâmica entre representações e práticas. A abordagem societal elaborada por Doise (2001) conceitua representações sociais como princípios organizadores de tomadas de posição, destacando as inserções sociais como fonte de variação. Especial atenção é dada à dimensão atitudinal das representações e às dimensões ideológicas que atualizam conteúdos representacionais em determinados contextos sociais.

A abordagem estrutural é marcada por um interesse central na organização do campo representacional, de modo que as relações que se estabelecem entre os elementos e a importância que cada um exerce na construção da representação social são o principal foco da análise (Abric, 2003).

Desde os trabalhos iniciais da abordagem estrutural, com Abric em 1976, as questões teórico-metodológicas estão no cerne do desenvolvimento da teoria das representações sociais (TRS). A equipe de Aix-en-Provence, liderada por Jean-Claude Abric e Claude Flament teve, desde o início, uma forte preocupação metodológica trabalhando em busca do desenvolvimento de instrumentos de coleta e de análise que pudessem comprovar as hipóteses teóricas contidas na teoria das representações sociais. Abric considerava que uma teoria só poderia se desenvolver se tivesse métodos e técnicas estritas (Santos \& Almeida, 2014). Visando o desenvolvimento de instrumentos específicos, foram criados softwares (SIMI, EVOC, Tri-deux-mots) e algumas técnicas de investigação da estrutura das representações sociais. Um dos marcos dessas investigações foi a criação dos testes de centralidade por Pascal Moliner (1992).

A associação livre configura-se como um dos instrumentos de coleta que ocupa posição de destaque dentro da TRS, proporcionando a apreensão rápida e fácil dos 
elementos constitutivos das representações sociais. Os anos 90 do século XX foram marcados por questionamentos acerca da eficácia da técnica de associação livre. Vergès propôs em 1994 que fosse somado um critério qualitativo ao critério quantitativo da frequência como indicador de hierarquia. Baseado nessas ideias, Abric (2003) propôs a utilização da associação livre a partir da consideração de dois tipos de indicadores de hierarquia: a frequência e a ordem de importância de um item. A atribuição de importância dos itens realizada pelo participante é uma informação qualitativa que acrescenta significação aos critérios quantitativos deste método.

Trabalhos atuais têm-se debruçado sobre as implicações da hierarquia de importância dos itens. O trabalho de Dany, Urdapilleta e Monaco (2014) sobre método de associação livre e representação social, apresenta algumas reflexões acerca da frequência e da ordem de importância na análise da associação livre de câncer e cuidados paliativos entre médicos e enfermeiros. Os resultados das associações livres, nesta pesquisa, demonstram que o uso de instruções de hierarquização durante a tarefa de associação livre não é neutro, uma vez que provoca mudanças nos campos representacionais. Esta mudança pode ser percebida, uma vez que os sujeitos podem se apoderar das instruções dadas para modificar a ordem espontaneamente estabelecida. O estudo demonstra ainda que este procedimento de instruir a hierarquia da ordem de importância pode deslocar os elementos inicialmente presentes no núcleo central para o sistema periférico, mudando assim o seu posicionamento.

Os anos 2000 do século XX marcaram uma continuidade dos avanços da abordagem estrutural, principalmente no que se refere a ganhos metodológicos, a partir do emprego da experimentação nos estudos articulados às atitudes (Tafani, 2001), à influência social (Tafani, Souchet, Codaccioni, \& Mugny, 2003) ou ainda aos aspectos e funções identitárias das representações sociais (Abric, 2003; Guimelli \& Deschamps, 2000).

Estes estudos focalizaram a dinâmica de funcionamento do núcleo central e do sistema periférico, sugerindo que o contexto social influencia a forma de enunciação dos elementos representacionais e consequentemente a sua organização e estruturação (Abric, 2001). Por exemplo, as respostas à tarefa de associação livre variam em função do modelo normativo que é ativado no momento de aplicação do questionário (Flament, 1999 citado em Abric, 2001). A hipótese da zona muda, objeto deste artigo, foi delineada no âmbito destes questionamentos (Guimelli \& Deschamps, 2000). Nos últimos 15 anos, assistimos à crescente investigação empírica desta hipótese ligada especialmente ao estudo do preconceito e às funções identitárias das representações.

Alguns objetos sociais tidos como estranhos ou desconhecidos podem despertar medo, pelo fato de ameaçar a ordem do grupo. A metáfora da AIDS como peste, por exemplo, remete à doença que vem de outro lugar, isto é, à ligação entre o imaginário 
da doença e o imaginário do estrangeiro. Dito de outra forma, a doença temida é encarada como doença de estrangeiro, ou, usando a terminologia de Sontag (1989), do outro que é identificado como não-nós, o estranho.

A expressão de Joffe "eu não, meu grupo não" também demonstra o processo de atribuir a causa da AIDS a grupos "estranhos" (excluídos socialmente) ou grupos estrangeiros (Joffe, 2012). O discurso sobre as doenças contagiosas atribui frequentemente a causa do mal ao outro, o mais longe possível e estranho de nós. Assim, esse tema provoca mobilizações grupais, processos de diferenciação entre os indivíduos para um distanciamento da doença e da possibilidade de contágio. O que evidencia a AIDS como um objeto de espessura e relevância social, suscitando dinâmicas intergrupais, e portanto, um bom exemplo para o estudo do preconceito.

Os estudos de preconceito têm mudado à medida que a sociedade evolui, transformando-se em um "vírus em evolução", terminologia utilizada por Vala (2013).

Os primeiros estudos sobre o preconceito foram realizados por Allport (1954). Segundo Allport (1954) o preconceito era tido como raciocínio falho ou sem fundamento, dirigido aos grupos socialmente desvalorizados. Percebe-se nesta visão a dimensão cognitiva, intrapessoal e interpessoal do preconceito. Já autores como Tajfel (1981) e Sherif (1967) estudaram o preconceito na ótica das relações intergrupais, isto é, no âmbito das relações de cooperação e conflito (Monteiro, 2013).

Atualmente, pesquisadores como Vala (2013), Lima e Vala (2004), Pereira, Torres e Almeida (2003), entre outros, têm-se debruçado sobre as mudanças nas formas de expressão do preconceito em virtude da presença das normas antipreconceito. Estes estudiosos ressaltam que as leis ou normas antipreconceito estão longe de ser mecanismos eficazes no combate ao preconceito e as novas formas de expressão que ele assume nos colocam diante da necessidade de aprimorar investigações e métodos de estudo deste fenômeno.

Do ponto de vista da teoria das representações sociais, alguns autores têm observado que em face de determinados objetos atravessados por preconceito, certos conteúdos são mascarados na situação da enquete, escapando à análise (Abric, 2003). Estamos perante o que o autor denomina "zona muda" das representações sociais. Ela surge como elementos contranormativos, portanto, não aparecem ou não são ativados, uma vez que marcariam o afastamento do sujeito das normas do grupo a que pertence. Contudo, a "zona muda" pode aparecer quando for reduzida a pressão normativa. Diante dos fatos ou valores morais reconhecidos e socialmente aceitáveis, os sujeitos optam em preservar tais valores ao invés de expressarem aquilo que vai contra o que é socialmente desejável.

Segundo Abric (2003), a pressão normativa se origina a partir de dois elementos: o sujeito e seu grupo de pertença. Ela influencia o participante na produção de expressões pró-normativas, durante a realização do questionário. As respostas do 
participante, ao sofrer influência da pressão normativa, tendem a expressar elementos selecionados com a função de se manter "bem visto" perante seu grupo de referência.

Com o intuito de "desmascarar" a zona muda das representações sociais, Abric (2003) propõe duas técnicas que facilitam a redução da pressão normativa, e consequentemente a expressão dos elementos contranormativos que compõem a zona muda. Uma delas é a técnica de substituição, que busca reduzir a implicação do sujeito no seu grupo de pertença. Por meio da técnica de substituição o participante é solicitado a responder a associação livre em nome do seu grupo de pertença, em substituição ao questionário que se dirige diretamente ao sujeito como fonte. Já a técnica de descontextualização normativa busca variar os contextos de pressão normativa, afastando ou aproximando o sujeito do seu contexto de origem ou grupo de pertença, permitindo que se expresse com maior ou menor liberdade (Abric, 2003).

No Brasil, a abordagem estrutural da teoria das representações sociais é uma das escolas mais difundidas (Santos, Morais, \& Acioli Neto, 2012) e nos últimos anos, alguns pesquisadores brasileiros têm se debruçado sobre seus aspectos metodológicos, notadamente acerca da técnica de evocação ou associação livre de palavras e suas formas de análise (Wachelke \& Wolter, 2011).

No estudo de Oliveira (2013), por exemplo, foi constatado o desmascaramento da "zona muda" das representações sociais, a partir da condição normal de aplicação e da técnica de substituição. Na condição normal da aplicação, os aspectos positivos de enfretamento da $A I D S$, como precaução e tratamento foram realçados. $\mathrm{Na}$ substituição, situação na qual os sujeitos foram solicitados a responder em nome do grupo, reduzindo com isso a pressão normativa, os elementos negativos como medo, preconceito e homossexualidade foram realçados.

No estudo de Piermattéo, Lo Monaco, Moreau, Girandola e Tavani (2014) sobre as representações sociais de cigano foi utilizada a técnica de descontextulização normativa. Os entrevistados foram solicitados a expressar suas ideias sobre os ciganos em duas condições: na primeira eles se expressavam diante do grupo (contexto público), na segunda condição eles se expressavam individualmente por escrito (contexto privado). A técnica de descontextualização normativa consistia no modo como o pesquisador se apresentava aos sujeitos: ora como cigano, ora como não cigano. Os resultados obtidos pelos pesquisadores, mostram que a condição de maior desmascaramento foi a condição privada na qual o entrevistador se apresentava como não cigano, ao passo que, a condição de maior mascaramento da zona muda foi a condição pública na qual o entrevistador se apresentou como cigano. Estes resultados mostram um efeito do pesquisador sobre a produção de observações - o fato de os participantes identificarem ou atribuírem uma origem étnico-racial ao pesquisador influencia a forma pela qual expressam conteúdos representacionais contranormativos. 
No presente trabalho, buscamos o desmascaramento da zona muda através da manipulação do efeito do pesquisador, controlando também, em uma tarefa de associação livre, a ordem de apresentação de dois termos indutores. Esta via se assemelha à técnica de descontextualização normativa, que consiste em variar a pressão normativa pelo controle do nível de implicação do sujeito. Procuramos minimizar a implicação do sujeito com a aplicação de um questionário por um pesquisador brasileiro e aumentar o nível de implicação do sujeito com o objeto de pesquisa por meio da aplicação do questionário por um pesquisador de origem africana.

Formulamos a hipótese segundo a qual conteúdos representacionais seriam diferentes em função do nível de implicação do participante: conteúdos explicitamente negativos seriam mascarados em face do pesquisador africano e desmascarados em face do pesquisador brasileiro. Estes conteúdos deveriam ainda ser influenciados pela ordem de apresentação dos termos indutores.

\section{MÉTODO}

\section{Participantes}

Participaram desta pesquisa 60 estudantes universitários de diferentes áreas. As ciências humanas e sociais aplicadas $(n=38)$, ciências da saúde $(n=16)$ e ciências exatas $(n=6)$. Ressaltamos que agrupamos área de ciências sociais aplicadas com as humanas, uma vez que a primeira é composta por apenas um participante. Foram 29 homens e 31 mulheres com idades entre 18 e 50 anos (média de idade de homens e mulheres $=22$ anos e desvio padrão é de 6.82). Trinta e oito participantes declararam ter uma religião e 22 declararam não possuir qualquer religião.

\section{Instrumento e procedimento}

Os participantes responderam a um questionário de evocação de palavras, composto por dois termos indutores (AIDS na África; Africano). Para cada um dos indutores apresentados foi solicitado que respondessem de forma espontânea, listando as primeiras palavras ou expressões que lhe viessem à mente. A ordem de apresentação destes indutores foi contrabalanceada, considerando AIDS na África o indutor 1 e Africano o indutor 2. Ou seja, metade dos participantes responderam ao questionário com o indutor 1 antes 
do indutor 2 e a outra metade com o indutor 2 em primeiro. Foram respeitados todos os procedimentos éticos para a realização de pesquisa com seres humanos. Aos participantes foram fornecidos oralmente todas as informações a respeito da pesquisa assim como a informação sobre sua livre participação e desistência. Eles ainda forneceram os respectivos emails para o envio posterior dos resultados da pesquisa.

Dois pesquisadores (um de origem africana e outro de origem brasileira) aplicaram o instrumento para participantes diferentes. Cada pesquisador aplicou o questionário para metade da amostra. Para a análise, a variação do pesquisador foi considerada uma variável da pesquisa. Este procedimento de mudança do pesquisador (africano e brasileiro) para cada metade da amostra visou o desmascaramento de uma possível zona muda, através de uma descontextualização normativa conforme método proposto por Abric (2003).

\section{Procedimentos de análise dos dados}

As palavras evocadas foram tratadas com ajuda do software trideux-mots versão 5.1. Trata-se de um software livre que, no campo de estudo das representações sociais, permite o exame dos conteúdos representacionais em função das condições de produção destes conteúdos e de variáveis previamente controladas como foi o caso desta pesquisa (Deschamps, 2003).

O uso do trideux-mots auxilia na identificação de variações de composição e organização dos campos lexicais a partir da análise das associações entre palavras e variáveis. Após a análise fatorial de correspondência, foi realizado o cálculo da contribuição média de cada palavra e de cada variável para cada fator obtido. Baseado na proposta de Deschamps (2003) dividiu-se a soma de todas as contribuições para o fator (que por convenção é sempre igual a 1000) pela soma de elementos retidos no fator, primeiro para as palavras e em seguida para as variáveis de cada campo lexical. Este procedimento seleciona as palavras e variáveis que possuem forte contribuição para os fatores e descarta da análise aquelas que apresentam contribuições inferiores à respectiva média. Observou-se que a média das contribuições para cada fator é idêntica para palavras e variáveis em ambos os indutores (Média-palavras = 66.6; Média-variáveis $=71.4$ ).

Para esta pesquisa, foi realizada uma análise de correspondência dos dois campos lexicais produzidos (AIDS na África; Africano). Duas condições de produção foram analisadas: a ordem de apresentação dos indutores e a aplicação pelo pesquisador africano ou pelo pesquisador brasileiro. Tais condições de produção foram inseridas no software como variáveis *indutor (1-AIDS na África ou 2-Africano) e *pesquisador (1- Africano ou 2-Brasileiro). As seguintes variáveis foram ainda estudadas: sexo (masculino ou feminino), religião (com ou sem religião), idade (entre 18 e 24 anos ou acima de 24), área de estudo (ciências humanas e sociais aplicadas, ciências da saúde e ciências exatas). 


\section{RESULTADOS}

\section{Campo lexical "AIDS na África”}

A análise dos resultados derivados da associação livre de palavras, a partir do termo indutor "AIDS na África" permitiu observar que as expressões associadas com maior frequência são: pobreza (26), morte (23), epidemia (12), falta de informação (11) e sofrimento (10). A palavra pobreza se destaca sendo evocada por 26 participantes (43.3\%) em um total de 60.

A partir dos resultados obtidos na Análise Fatorial de Correspondência (AFC) foi possível obter dois fatores, que vamos explicar a seguir. Após a análise da contribuição média de cada palavra e variável para cada fator, verificou-se que a contribuição das palavras mais frequentes, como pobreza, morte, falta de informação (ver Tabela 1) é menor do que a contribuição média para os dois fatores. Essas palavras, portanto, foram retiradas da projeção (Figura 1).

A partir da distribuição dos resultados pela análise fatorial, observou-se que o fator 1 contribuiu para explicar $41.6 \%$ do conteúdo analisado. Já o fator 2 contribuiu com 21.3\%. Para esta análise apenas os fatores 1 e 2 foram considerados, atingindo $62.9 \%$ da inércia.

Tabela 1

Frequências e Contribuições para os Fatores 1 e 2 das Evocações e Variáveis

\begin{tabular}{lccccccccccc}
\hline \multicolumn{1}{c}{ AIDS na África } & \multicolumn{10}{c}{ Africano } \\
\hline Evocações & F & F=1 & CPF1 & F=2 & CPF2 & Evocações & F & F=1 & CPF1 & F=2 & CPF2 \\
\hline Falta de & 4 & -356 & 59 & -442 & 177 & Sofre & 4 & 577 & 92 & 34 & 2 \\
prevenção & & & & & & & & & & & \\
Guerras & 4 & -87 & 3 & -31 & 1 & Guerras & 4 & 571 & 90 & 444 & 280 \\
Doença & 4 & -129 & 8 & 503 & 230 & Guerreiro & 4 & -503 & 70 & 216 & 66 \\
Cultura & 4 & -73 & 3 & -57 & 3 & Dança & 4 & -699 & 135 & 13 & 0 \\
Tristeza & 4 & -417 & 81 & -108 & 11 & Multicultu- & 4 & -503 & 70 & 216 & 66 \\
& & & & & & ralidade & & & & & \\
Falta de & 4 & -130 & 8 & -287 & 75 & Preconceito & 4 & -385 & 41 & -25 & 1 \\
conhecimento & & & & & & & & & & & \\
Abandono & 5 & 539 & 169 & 70 & 6 & Desigual & 5 & 305 & 32 & 23 & 1 \\
Preconceito & 6 & -376 & 99 & 471 & 303 & Escravidão & 6 & -62 & 2 & -142 & 43 \\
Descaso & 8 & 631 & 371 & 47 & 4 & Doenças & 6 & 184 & 14 & -235 & 117 \\
Prevenção & 9 & -270 & 77 & 67 & 9 & Fome & 8 & 141 & 11 & -183 & 95 \\
Sofrimento & 10 & 22 & 1 & 203 & 94 & Alegria & 12 & -369 & 112 & 78 & 26
\end{tabular}




\begin{tabular}{lccccccccccc} 
Falta de & 11 & 27 & 1 & 15 & 1 & Força & 12 & 320 & 85 & 219 & 204 \\
informação & & & & & & & & & & & \\
Epidemia & 12 & 231 & 75 & -35 & 3 & Pobreza & 13 & 275 & 68 & -126 & 73 \\
Morte & 23 & 57 & 9 & -90 & 43 & Cultura & 19 & -335 & 147 & -39 & 10 \\
Pobreza & 26 & -111 & 37 & -83 & 41 & Negro & 30 & 125 & 32 & -39 & 16 \\
\hline Variáveis & $\mathbf{F}$ & $\mathbf{F}=\mathbf{1}$ & $\mathbf{C P F 1}$ & $\mathbf{F}=\mathbf{2}$ & $\mathbf{C P F 2}$ & Variáveis & $\mathbf{F}$ & $\mathbf{F}=\mathbf{1}$ & $\mathbf{C P F 1}$ & $\mathbf{F}=\mathbf{2}$ & $\mathbf{C P F 2}$ \\
\hline Sexo1 & - & 246 & 74 & 256 & 156 & Sexo1 & - & 412 & 154 & 204 & 142 \\
Sexo2 & - & -218 & 66 & -227 & 138 & Sexo2 & - & -301 & 112 & -149 & 104 \\
Idade1 & - & 68 & 10 & 5 & 0 & Idade1 & & -53 & 6 & 0 & 0 \\
Idade2 & - & -365 & 54 & -28 & 1 & Idade2 & & 547 & 57 & 3 & 0 \\
Área1 & - & 279 & 116 & -41 & 5 & Área1 & - & 261 & 91 & -51 & 13 \\
Área2 & - & -367 & 94 & -276 & 104 & Área2 & - & -468 & 122 & 95 & 19 \\
Área3 & - & -659 & 152 & 753 & 386 & Área3 & - & -345 & 30 & 62 & 4 \\
& - & 1211 & 85 & -144 & 2 & & - & 0 & 0 & 0 & 0 \\
Religião1 & - & -157 & 40 & -38 & 5 & Religião1 & & -85 & 11 & -44 & 11 \\
Religião2 & - & 256 & 65 & 62 & 8 & Religião2 & & 202 & 26 & 104 & 26 \\
Pesquisador1 & - & -198 & 59 & -65 & 12 & Pesquisador1 & - & -352 & 150 & 10 & 0 \\
Pesquisador2 & - & 275 & 83 & 90 & 17 & Pesquisador2 & - & 453 & 193 & -12 & 1 \\
Indutor 1 & - & 212 & 54 & -195 & 89 & Indutor 1 & - & 139 & 22 & -267 & 313 \\
Indutor 2 & - & -182 & 47 & 168 & 77 & Indutor 2 & - & -163 & 26 & 315 & 368 \\
\hline Nota. F: freqén
\end{tabular}

Nota. F: frequência; $\mathrm{F}=1$ : fator 1; $\mathrm{CPF} 1$ : contribuição para o fator 1; $\mathrm{F}=2$ : fator 2; $\mathrm{CPF}$ : contribuição para o fator 2 .

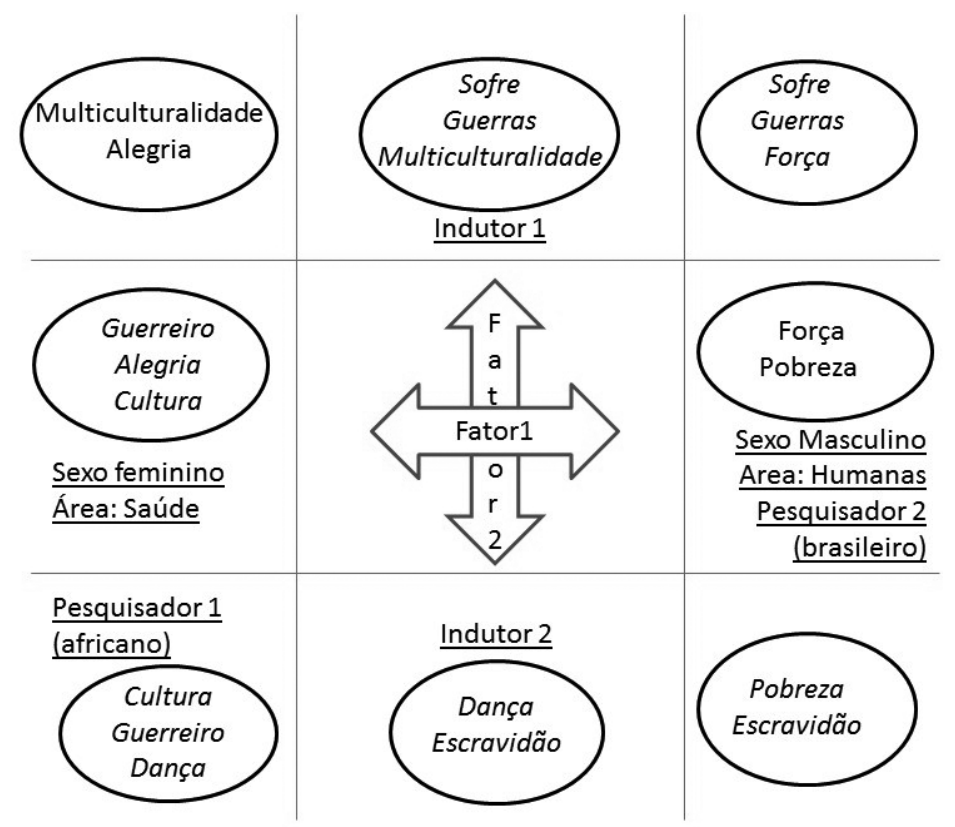

Africano

Figura 1. Principais resultados das evocações no campo lexical AIDS na África. 
Para o fator 1 as palavras com maior contribuição são: descaso, abandono, tristeza, epidemia e prevenção. No polo positivo estão posicionadas as palavras descaso, abandono e epidemia enquanto prevenção e tristeza estão posicionadas no polo negativo deste fator (ver Figura 1). Contribuem ainda para este fator as variáveis área das ciências humanas e sociais aplicadas e pesquisador 2 (brasileiro). Todas localizadas no polo positivo.

Para o fator 2 as palavras com maior contribuição são: preconceito, doença, falta de prevenção e sofrimento. No polo positivo estão posicionadas as palavras doença, preconceito e sofrimento enquanto falta de prevenção e falta de conhecimentos se posicionam no polo negativo deste fator. Contribuem ainda para este fator, as variáveis sexo, indutor, áreas humanas e sociais aplicadas e da saúde. As variáveis em associação com as palavras posicionadas no polo positivo do fator 2 são: sexo masculino e indutor 2 ao passo que sexo feminino, indutor 1 , áreas humanas e sociais aplicadas e da saúde se posicionam no polo negativo.

\section{Campo lexical “Africano"}

A análise dos resultados derivados da associação livre de palavras, a partir do termo indutor Africano permitiu observar que as palavras associadas com maior frequência são: negro (30), cultura (19), pobreza (13), alegria (12) e força (12). A palavra negro se destaca, sendo evocada por 30 participantes $(50 \%)$ num total de 60 .

A seguir vamos explicar os resultados obtidos na Análise Fatorial de Correspondência (AFC). Após a análise da contribuição média de cada palavra e variável para cada fator obtido (ver Tabela 1), verificou-se que a contribuição da palavra mais frequente, negro, é menor que a contribuição média para os dois fatores. Essa palavra, portanto, foi retirada da projeção.

A partir da distribuição dos resultados pela análise fatorial, observou-se que o fator 1 contribuiu com 56.4\% para explicar o conteúdo analisado. Já o fator 2 contribuiu com 15\%. Para esta análise, apenas os fatores 1 e 2 foram considerados, atingindo $71.4 \%$ da inércia. 


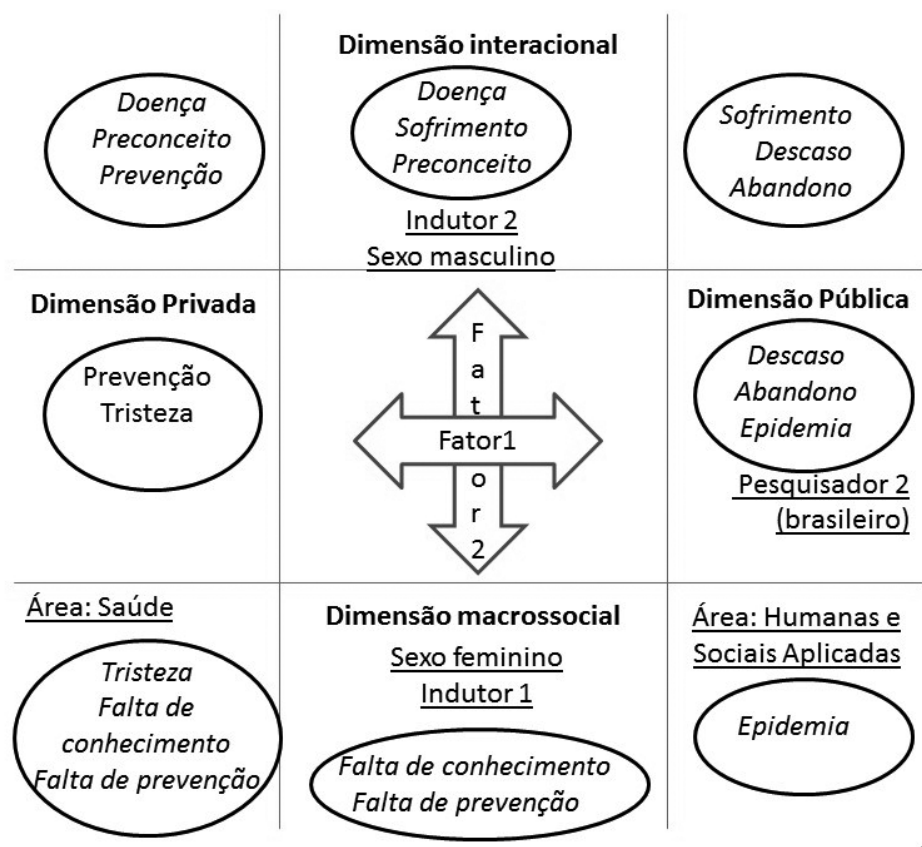

Aids na África

Figura 2. Principais resultados das evocações no campo lexical Africano

Para o fator 1, as palavras com maior contribuição são: guerreiro, alegria, força, pobreza e cultura. No polo positivo estão posicionadas força e pobreza enquanto guerreiro, alegria e cultura estão posicionadas no polo negativo deste fator (Ver Figura 2). Contribuem ainda para este fator as variáveis sexo, áreas humanas e sociais aplicadas e da saúde, pesquisador 2 (brasileiro). No polo positivo contribuem as variáveis: sexo masculino, área das ciências humanas e sociais aplicadas e pesquisador 2 (brasileiro) enquanto no polo negativo contribuem as variáveis sexo feminino é área das ciências da saúde.

Para o fator 2 a maior contribuição é das palavras sofre, guerras, dança, multiculturalidade e escravidão. No polo positivo estão posicionadas sofre, guerras, multiculturalidade enquanto dança e escravidão se posicionam no polo negativo deste fator. Contribui ainda para este fator a variável indutor. No polo positivo, o indutor 1 (AIDS na África) e no polo negativo o indutor 2 (Africano).

\section{DISCUSSÃO}

Podemos identificar a partir dos dados analisados a presença de antinomias na organização do campo lexical AIDS na África. A primeira antinomia se estrutura a 
partir das influências do primeiro fator e opõe as noções de "público" e "privado". Desta forma, as palavras descaso, abandono e epidemia parecem contribuir para um discurso que ultrapassa um nível individual, construindo um sentido de coletividade sobre a doença. Conteúdos representacionais do polo positivo delimitam assim a dimensão pública relacionada ao fenômeno da AIDS na África, ativando um processo de causalidade externa ao fenômeno quando o indutor 1 é apresentado em primeira posição. Este polo aparece associado ao sexo masculino, área de formação de ciências humanas e sociais aplicadas e apresentação em primeira ordem do indutor 1 (AIDS na África). A dimensão pública é enfatizada quando testamos o efeito da ordem de apresentação dos indutores, ou seja, quando o termo Africano não é apresentado em primeira posição. Este efeito aparece também como relevante na análise do segundo fator que será discutido mais adiante.

A dimensão "privada" aparece ligada ao polo negativo do primeiro fator, associada notadamente aos conteúdos representacionais tristeza e prevenção. O termo prevenção tomado em separado pode remeter também à dimensão pública, entretanto, em conjunto com a palavra tristeza parece apontar para uma perspectiva singularizada. São elementos que remetem a um nível individual de explicação do fenômeno da AIDS na África, ou seja, a uma dimensão interna na atribuição de causalidade. O efeito da ordem de apresentação dos indutores se manifesta reforçando esta antinomia (público x privado). Neste sentido, quando o indutor 2 é apresentado na primeira posição, parece induzir conteúdos de nível individual ao campo lexical AIDS na África.

A construção da polarização do fator 1 aparece associada à área de formação dos participantes. A dimensão societal (macrossocial e pública) é destacada pelos participantes com formação na área de ciências humanas e sociais enquanto a dimensão das relações humanas (interacional e privado) é enfatizada pelos participantes da área de saúde. Do ponto de vista empírico, embora restritos, os dados desta pesquisa permitem uma reflexão sobre a formação de profissionais e o fenômeno de atribuição de causalidade. Enquanto os estudantes com formação biomédica parecem buscar explicações que responsabilizam o indivíduo, em um processo de atribuição de causalidade interna, os estudantes da área de ciências humanas e sociais destacam os aspectos macropolíticos, atribuindo, assim, causalidade externa para explicar a AIDS na África.

A segunda antinomia se estrutura a partir das influências do segundo fator e opõe as dimensões interacional e macrossocial. No polo positivo as palavras sofrimento e preconceito destacam as consequências que a doença pode acarretar no âmbito das relações sociais. Neste polo a apresentação do indutor 2 (Africano) em primeira ordem parece influenciar a ligação que os sujeitos fazem da AIDS com suas consequências, consideradas como nefastas e podendo polarizar as relações sociais, conforme aponta Herzlich e Pierret (2005). 
Já o polo negativo reúne as expressões falta de conhecimento e falta de prevenção que constituem conteúdos representacionais que conferem à AIDS uma dimensão explicativa macrossocial. Neste polo, quando o indutor 1 (AIDS na África) é apresentado em primeira ordem parece induzir a ligação da AIDS no continente africano com a falta de conhecimento e a falta de prevenção possivelmente provocados pela ausência de ação governamental.

Do ponto de vista metodológico, nossos resultados apontam a necessidade de uma atenção especial do pesquisador para o efeito da ordem de apresentação do termo indutor em uma associação livre, que tem consequências diretas na produção de dados. A apresentação da expressão AIDS na África em primeira ordem parece ter mobilizado conteúdos vinculados a uma explicação em uma dimensão societal. Por outro lado, quando o termo indutor Africano foi apresentado em primeira ordem parece ter mobilizado conteúdos ligados à pessoa humana, ao sujeito que vive na África, destacando-se, portanto, as dimensões das emoções e interações humanas. Esse efeito organiza a construção tanto da antinomia público x privado quanto da segunda antinomia observada: a dimensão interacional x macrossocial.

Os nossos achados corroboram com o estudo de Piermattéo, Lo Monaco, Moreau, Girandola e Tavani (2014) em que foi utilizada a técnica de descontextualização normativa na representação social dos ciganos. No nosso estudo, a presença do pesquisador africano e brasileiro favorece respectivamente o mascaramento e desmascaramento da zona muda. Porém, diferentemente do estudo citado, verificamos que a apresentação da ordem dos indutores (Aids na África e o Africano) alternadamente influencia a produção distinta dos conteúdos representacionais.

Vale ressaltar, ainda, que a ordem de apresentação dos indutores não é a única questão a que o pesquisador deve estar atento. Os indutores utilizados nesta pesquisa englobam sentidos diferentes. O indutor AIDS na África é impessoal, e remete a doença para um determinado contexto, ao passo que Africano remete para a ideia da pessoa que é originária desse contexto. Assim, na análise dos dois campos lexicais estudados, observaram-se efeitos diferentes da ordem de apresentação dos indutores. Para o campo lexical AIDS na África houve uma maior influência do controle da ordem dos indutores para estruturação das explicações em termos de antinomias. Entretanto, para o campo lexical Africano o que mais chama atenção é o jogo de estereótipos que acontece diante de um pesquisador brasileiro ou africano. Nesse sentido, a discussão dos dados a partir do campo lexical Africano tem como foco a análise do efeito do pesquisador pela técnica de descontextualização normativa (Abric, 2003).

Como observado na Figura 2, a variável pesquisador aparece fortemente associada à organização dos conteúdos representacionais no primeiro fator. Diante do pesquisador africano, estereótipos positivos como cultura, guerreiro e alegria foram salientados (polo negativo). Enquanto, apenas face ao pesquisador brasileiro, surgem conteúdos 
atrelados a estereótipos negativos, como pobreza (polo positivo). Ressaltamos, ainda, que este efeito de desmascaramento é evidenciado também no segundo fator.

Ao analisar a combinação entre os polos dos fatores, percebe-se o efeito de uma possível zona muda (Abric, 2003) influenciado pelo controle do pesquisador (origem brasileira e origem africana). Estereótipos positivos são unicamente ativados na presença do pesquisador africano (multiculturalidade; alegria; cultura; guerreiro e dança), de modo que conteúdos negativos são silenciados. Estes conteúdos silenciados são ativados na presença do pesquisador brasileiro, ressaltando estereótipos negativos sobre o Africano (sofre; guerra; pobreza e escravidão).

Embora diante do pesquisador africano não apareça demonstração clara do preconceito com relação aos Africanos, não podemos descartar a sua existência, pois ele pode ser expresso também por meio de estereótipos positivos como guerreiro. Isso quer dizer que o preconceito pode ser manifesto nas sutilezas por meio da ênfase em características positivas, como identificado por Lima (2013), a partir de dados comparativos sobre novas formas sofisticadas de preconceitos com negros no Brasil.

\section{CONSIDERAÇÕES FINAIS}

A presente investigação possui um valor heurístico para pensar estratégias metodológicas no estudo do desmascaramento da zona muda das representações sociais. Ao analisar conteúdos representacionais evocados a partir de dois termos indutores, foi possível identificar diferentes estruturas sociocognitivas na ativação destes conteúdos. Como dito anteriormente, o campo lexical AIDS na África é organizado a partir de um fenômeno de atribuição de causalidade: interno x externo. Desta forma, para este campo lexical, os conteúdos ligados às dimensões público x privado; interacional $\mathrm{x}$ macrossocial sofrem a influência da ordem de apresentação dos termos indutores e da formação dos participantes, enquanto o campo lexical Africano se estrutura por meio do jogo de estereótipos (positivos e negativos) modulado pela descontextualização normativa e operada pela variação de pesquisador na aplicação do instrumento. Portanto, a ordem de apresentação dos indutores e a aplicação por pesquisadores diferentes ativaram conteúdos representacionais ligados a processos psicossociais distintos (atribuição de causalidade; produção de estereótipos).

A análise do efeito da variável sexo constitui um limite desta pesquisa, visto que, durante a aplicação dos questionários, não foi estabelecida a equivalência entre sexos nas diferentes áreas de formação. Em função deste desequilíbrio não podemos interpretar os efeitos dessa variável. Para o presente estudo a área de formação constitui uma variável importante por se relacionar com a fonte de informação 
que pode gerar explicações sobre os fenômenos investigados. Encorajamos os pesquisadores a levarem em conta estes aspectos em estudos futuros.

\section{REFERÊNCIAS}

Abric, J. C. (2001). L'approche structurale des représentations sociales: Développements récents. Psychologie et Société, 2(4), 81-104.

Abric, J. C. (2003). La recherche du noyau central et de la zone muette des représentations sociales. In J. C. Abric (Ed.), Méthodes d'études des représentations sociales (pp. 59-75). Érès: Ramonville Saint-Agne.

Abric, J-C. J. (1976). Jeux, Conflits et représentations sociales, Thèse de doctorat, Université de Pronvence, Aix-en-Provence.

Allport, G. (1954). The nature of prejudice. Reading: Addison-Wesley.

Dany, L., Urdapilleta, I., \& Monaco, G. L. (2014). Free associations and social representations: Some reflections on rank-frequency and importance-frequency methods. Quality \& Quantity, 49(2), 489-507. doi:10.1007/s11135-014-0005-z

Deschamps, J. C. (2003). Analyse des correspondances et variations des contenus des représentations sociales. In J. C. Abric (Ed.), Méthodes d'étude des représentations sociales (pp. 179-200). Ramongville-Saint Agne: Erès.

Doise, W. (2001). Droits de l'homme et forces des idées, Paris: Presses Universitaires de France.

Guimelli, C., \& Deschamps, J. C. (2000). Effets de contexte sur la production d'associations verbales: Le cas des représentations sociales des Gitans. Cahiers Internationaux de Psychologie Sociale, 47(48), 44-54.

Jodelet, D. (1989). Folies et représentations sociales. Paris: Presses Universitaires de France.

Joffe, H. (2012). "Eu-não, meu-grupo-não”: Representações sociais transculturais da AIDS. In P. Guareschi \& S. Jovchelovitch (eds.), Textos em representações sociais (pp. 239-265). Petrópolis: Vozes.

Jovchelovitch, S. (2012). Vivendo a vida com os outros: Intersubjetividade, espaço público e representações sociais. In P. Guareschi \& S. Jovchelovitch (eds.), Textos em representações sociais (pp. 63-85). Petrópolis: Vozes.

Herzlich, C., \& Pierret, J. (2005). Uma doença no espaço público: A AIDS em seis jornais franceses. Physis, 15, 71-101. doi: 10.1590/S0103-73312005000300005

Lima, M. E. O. (2013). Preconceito. In L. Camino, A. R. R. Torres, M. E. O. Lima, \& M. E. Pereira (eds.), Psicologia social: Temas e teorias (pp. 589-642). Brasília Technopolitik.

Lima, M. E. O., \& Vala, J. (2004). As novas formas de expressão do preconceito e do racismo. Estudos de Psicologia, 9, 401-411. doi: 10.1590/S1413-294X2004000300002

Moliner, P. (1992). Structure de représentation et structure de schèmes. Les Cahiers Internationaux de Psychologie Sociale, 14, 48-52.

Monteiro, M. B. (2013). Relações intergrupais. In J. Vala \& M. B. Monteiro (eds.), Psicologia social (9a ed., pp. 493-568). Lisboa: Fundação Calouste Gulbenkian.

Moscovici, S. (2012). A psicanálise, sua imagem e seu público. Petrópolis, RJ: Vozes.

Oliveira, D. C. (2013). Construção e transformação das representações sociais da aids e implicações para os cuidados de saúde. Revista Latino-Americana de Enfermagem, 21(Spec.), 276-86. doi: 10.1590/S0104-11692013000700034 
Pereira, C. R., Torres, A. R. R., \& Almeida, S. T. (2003). Um estudo do preconceito na perspectiva das representações sociais: Análise da influência de um discurso justificador da discriminação no preconceito racial. Psicologia Reflexão e Crítica, 16, 95-107. doi: 10.1590/S0102-79722003000100010

Piermattéo, A., Lo Monaco, G., Moreau, L., Girandola, F., \& Tavani, J. L. (2014). Context variations and pluri-methodological issues concerning the expression of a social representation: The example of the gypsy community. The Spanish Journal of Psychology, 17. doi: 10.1017/sjp.2014.84

Santos, M. F. S., Morais, E. R. C., \& Acioli Neto, M. L. (2012). A produção científica em representações sociais: Análise de dissertações e teses produzidas em Pernambuco. Psico, 43(2), 200 207. Consultado em http://revistaseletronicas.pucrs.br/fo/ojs/index.php/revistapsico/article/ view/11697/8043

Santos, M. F. S., Almeida, A. M. O. (2014). Entrevista com Jean-Claude Abric. [DVD]. Laboratório de Interação Social Humana (UFPE)/Centro Internacional de Pesquisa em Representação e Psicologia Social.

Sherif, M. (1967). Social interaction: Process and products. Chicago: Aldine Publ. Company.

Sontag, S. (1989). AIDS e suas metáforas. (P. H. Britto \& R. Figueiredo, Trad.). São Paulo: Companhia das Letras. (Obra original publicada em 1988).

Tafani, E. (2001). Attitudes, engagement et dynamique des représentations sociales: Études expérimentales. Revue Internationale de Psychologie Sociale, 14(1), 7-30.

Tafani, E., Souchet, L., Codaccioni, C., \& Mugny, G. (2003). Influences majoritaire et minoritaire sur la représentation sociale de la drogue. Nouvelle Revue de Psychologie Sociale, 2(3), 343-354.

Tajfel, H. (1981). Grupos humanos e categorias sociais, Vol. I, Lisboa: Livros Horizonte.

Tajfel, H. (1983). Grupos humanos e categorias sociais, Vol. II, Lisboa: Livros Horizonte.

Vala, J. (2013). Racisms: Social representations, racial prejudice and normative pressures. Papers on Social Representations, 22, 6-29.

Vergès, P. (1994). Approche du noyau central: Propriétés quantitatives et Structurales. In C. Guimelli (ed.), Structures et transformations des représentations sociales (pp. 233-253). Neuchâtel: Delachaux et Niestlé.

Wachelke, J., \& Wolter, R. (2011). Critérios de construção e relato da análise prototípica para representações sociais. Psicologia: Teoria e Pesquisa, 27(4), 521-526. doi: 10.1590/S0102-37722011000400017 